\title{
Interaction between sea water, groundwater flow systems, the occurrence and direction of buoyancy forces under hydrostatic conditions $[A]$, the direction of equivalent forces under hydrodynamic conditions $[B]$ in groundwater flow systems, and the occurrence of buoyancy reversal
}

\author{
Klaus Udo Weyer ${ }^{1}$
}

Received: 19 October 2018 / Accepted: 20 April 2019 / Published online: 29 May 2019

(c) The Author(s) 2019

\begin{abstract}
It is a part of normal scientific evolution that widely accepted scientific opinions are eventually supplanted by new insights. Naturally, the change of such basic scientific insights may ruffle the feathers of established proponents of previous held opinions. This situation has now arisen with respect to some of the basic assumptions of groundwater flow calculations. It presently also occurs in the basic physics of groundwater flow, namely the conflict between the application of velocity potentials and force potentials and, in addition, the application of pressure potential force directions within such calculations. Unfortunately, based on the physics involved, the necessary changes require a rewrite of some aspects of groundwater flow programs. It is clear that such changes will not be accepted without substantial resistance. However, these changes are, nevertheless, necessary for improving the knowledge and understanding of groundwater flow and its role in environmental sciences. The present shortcomings occur in two areas: (a) our understanding of the physics of variable density flow and (b) our choices on how to program codes for groundwater flow calculations. This paper deals with the field situation of variable density flow in Florida and in particular with the Cutler site. A physics-enhanced application of force potentials is dealt by Weyer (Environ Earth Sci, 2019) submitted to Environmental Earth Sciences. A selected collection of papers dealing with the physics of groundwater flow and the application of force potentials is contained in Weyer and Ellis (Subsurface investigation and simulation of fluid flow systems by means of force potentials. Springer Publications, New York, 2019).
\end{abstract}

Keywords Coastal aquifer $\cdot$ Seawater intrusion $\cdot$ Density-driven flow $\cdot$ Buoyancy $\cdot$ Buoyancy reversal

\section{Introduction}

I am pleased to have read the clearly worded rebuttal contribution by Provost et al. (2018) as it provides an opportunity to clarify, within the context of their statements, some of the

In answer to a rebuttal by A.D. Provost, A.D. Werner, V.E.A. Post, H.A. Michael and Ch. D. Langevin to my paper "The case of the Biscayne Bay and aquifer near Miami, Florida: density-driven flow of seawater or gravitationally driven discharge of deep saline groundwater?" by K.U. Weyer in Environmental Earth Sciences 77:1-16, 2018. https://doi.org/10.1007/s12665-017-7169-5.

Klaus Udo Weyer

weyer@wda-consultants.com

1 WDA Consultants Inc, Calgary T3A 0W7, Canada physics involved in the flow of fresh and saline groundwater on land and in coastal areas in Florida and elsewhere.

Reviewers of journal papers, on occasion, present strong judgements based on personal opinions colored by their scientific education and past scientific history. The process of peer review is known to have flaws with respect to groupthink and reluctance to accept new concepts. The Germanlanguage Springer journal 'Grundwasser' printed, however, a commentary in English outlining future developments to be expected in groundwater sciences (Weyer 2017). 


\section{Groundwater flow systems in Florida}

It is remarkable that the rebuttal by Provost et al. (2018) refers to groundwater flow systems basically only in one quotation from my paper although, in Florida, flow patterns originating inland and at the coast are dominated by local and far-reaching groundwater flow systems. The above authors' attention, however, is only concentrated on flow of seawater which they propose to essentially migrate inland along equipotential lines (see Weyer 2018, Fig. 2, taken from Langevin 2001, Fig. 15; also Weyer 2018, Figs. 8 and 9, taken from Cooper et al. 1964, Figs. 16 and 17) as a salt water wedge from the sea into coastal areas due to the incorrectly assumed driving action of density effects under hydrodynamic conditions. To my surprise, they also concern themselves with Hubbert's (1940) derivation of force potentials and not with Muskat's (1937) velocity potential as has been predominantly done in much of engineering sciences in the past. It appears, however, that they may not be familiar with the complex physics of groundwater flow systems and the application of force potentials as summarized and applied in Weyer (1978, 2018).

The knowledge of regional groundwater flow systems was developed in the 1960s (Tóth 1962, 1963; Freeze and Witherspoon 1967) well after the publications by Hubbert (1940, 1953). However, only these two Hubbert publications form the basis and physical framework of the comments by Provost et al. (2018). In those comments, the presence and physics of groundwater flow systems has thereby been ignored, a major shortcoming indicating a lack of familiarity with the occurrence and physics of groundwater flow systems. Provost et al. (2018) also do not consider new developments regarding the application of force potentials along pressure potential gradients as outlined by Weyer (2019). About a decade ago, Tóth (2009) published an introductory textbook on groundwater flow systems which was also not considered by Provost et al. (2018).

Gravity is the motor for groundwater flow systems. The modifying force fields are the pressure potential fields $[-(1 / \rho) \operatorname{grad} p]$, not simply grad $\mathrm{p}$ which ignores the density $\rho$ as applied by Provost et al. (2018). The pressure potential field is created by storing unused gravitational energy, which then can be released to augment energy gradients in support of greater flow through low permeable layers. The pressure potential field serves to store unused gravitational energy by compression of the fluid (here: water) and also to minimize the total energy consumption. It should be noted that the well-known text books by Bear (1972) and de Marsily (1986) assume water to be incompressible and thereby reject Hubbert's $(1940,1953)$ physics which is based on the compressibility of fluids. De Marsily (1986, p. 52, Eq. 3.3.2) states explicitly that the considered fluid is assumed to be incompressible and that Hubbert's method deals with compressible fluids. Of course, compressible fluids store energy by compression, incompressible fluids do not. Bear (1972) does not mention this restriction at all although he makes use of it.

The physical role of the density $\rho$ and the associated compression is seemingly not fully considered by Provost et al. (2018). They claim incorrectly that their Eq. (13) "is derived directly from Hubbert's force potential", [and] "holds whether the fluid is compressible or incompressible". They also seem to adhere to the opinion that mathematical procedures suffice to solve hydrodynamical problems thus ignoring part of the physics of fluid flow.

My publication on the large-scale groundwater flow systems in Florida and the particular situation at the Cutler site at Biscayne Bay took into account all of the above papers and concepts. The rebuttal by Provost et al. (2018), however, fails to incorporate references to the important and fundamental papers on groundwater flow systems, the effect of geologic structure, as well as to the effect of associated permeability distributions described by Tóth $(1962,1963$, 2009) and Freeze and Witherspoon (1967). Thereby they do not consider groundwater flow systems on land and groundwater discharge at the coast of the Florida Peninsula, and the associated artesian (flowing) conditions. Instead, their conceptual model is limited to landward-directed inflow and subsequent return flow of a mixture of fresh groundwater and seawater which is physically flawed. Groundwater flow pattern at the Cutler site and along the rest of the Florida coast and at comparable coast lines elsewhere are thus not interpreted correctly.

\section{Physics and appearance of groundwater flow on the Florida Peninsula}

Apparently, Provost et al. (2018) did not fully consider the physical meaning of Fig. 11 in Weyer (2018) taken from a publication of the USGS (Springfield 1966). Springfield's report documents artesian (flowing) discharge of deep groundwater flow systems to the surface in all of southern Florida including the coastal area in general and the area of Biscayne Bay in particular. Instead they re-adopt the outdated concept of density-driven flow pattern within groundwater flow systems proposed by Kohout (1964) and by Cooper et al. (1964) namely from the sea along equipotential lines (!) into the bottom of a limited part of the coastal aquifer and then with an upward directed curvature back to the sea as outlined with red arrows in Weyer (2018, Fig. 7). In doing so they ignore the upward flow of deep groundwater from more central parts of Florida 
into the coastal area (Weyer 2018, Figs. 8 and 9). In their opinion, which is not supported by field data, the salt water originates from Biscayne Bay and is only overlain with a relatively thin layer of freshwater originating from rain falling onto land as, for example, along the coastal low hills of Florida (Weyer 2018, Fig. 1), near Biscayne Bay. Henry (1964) goes even further by restricting groundwater flow in the Biscayne aquifer to a single permeable aquifer underlain and overlain by impermeable aquitards not present in the field. The available piezometric data show the interpretations of Cooper et al. (1964), Henry (1964), and Provost et al. (2018) to be physically incorrect.

Moreover, Springfield (1966, Fig. 28; reproduced as Fig. 11 in Weyer 2018) had already identified all of southern Florida, including the Biscayne area, as an artesian (flowing) groundwater discharge area with upwardsdirected groundwater flow from greater depth. Springfield's (1966) insight makes the existence of seawater flow into the Floridian aquifers at the Biscayne site and at other sites along the Florida coast physically impossible under the natural conditions considered here. The speculative flow pattern assumed by the rebuttal authors in following Cooper et al. (1964) do not exist along the Florida coast under natural conditions. In the Florida Peninsula highly permeable karstic layers allow and create the regional groundwater flow pattern as shown in Weyer (2018) in Figs. 8, 9, and 14.

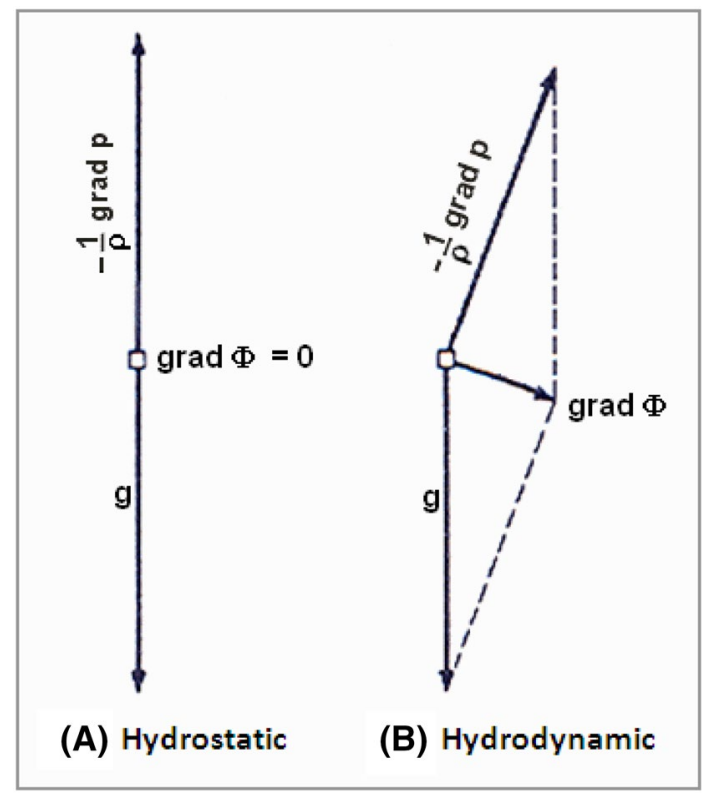

Fig. 1 Physical interpretation of force vectors: [A] hydrostatic conditions as assumed by Provost et al. (2018); [B] hydrodynamic case within groundwater bodies (after Hubbert 1953, Fig. 4)

\section{Buoyancy forces}

In the last part of their rebuttal, Provost et al. (2018) attempt to derive, from selected parts of Hubbert's work, an all-encompassing vertical buoyancy force for the entire groundwater body. Their underlying assumption is that the buoyancy force can only be derived from the Principle of Archimedes. Furthermore, as the Principle of Archimedes by definition deals with vertically upwards-directed forces in a hydrostatic environment, buoyancy forces per se, in their opinion, are directed vertically upwards under both hydrostatic and hydrodynamic conditions throughout the groundwater body. This interpretation is also reflected in the well-known computer programs they quote, such as SUTRA (Voss and Provost 2002), SEAWAT (Langevin et al. 2008), and FEFLOW (Diersch 2014). Weyer (2018) has shown this interpretation to be incorrect from a physics point of view under hydrodynamic conditions.

Under hydrostatic conditions (where groundwater does not flow, but remains static) the authors rightfully consider the forces $[-(1 / \rho) \operatorname{grad} p]$ as causing buoyancy to be directed vertically upwards and to be caused by pressure differences based on the pressure potential field with increasing pressures towards greater depth. They apparently consider, under hydrodynamic pressure conditions (groundwater flows), the same vertical pressure distribution to be at work which would create the same vertically upwards-directed buoyancy forces. This opinion is physically incorrect (compare Fig. 1b).

In their rebuttal to Weyer (2018), Provost et al. (2018) insist that the pressure potential gradient $[-(1 / \rho) \operatorname{grad} p]$ would be directed vertically upwards under both conditions, in the hydrostatic case (Fig. 1a) and the hydrodynamic case (Fig. 1b). This contradicts Fig. 1 taken from Hubbert (1953). In this assertion they are, therefore, physically incorrect as becomes obvious when comparing in Fig. 1 the arrow directions of (A) [hydrostatic conditions] with (B) [hydrodynamic conditions]. Clearly, under hydrostatic conditions the density-related 'buoyancy force' can only occur in a vertical direction, either upwards if the buoyant fluid is lighter than the host fluid according to the Principle of Archimedes, or downward-directed if the considered fluid is heavier than the host fluid. This is, however, not the case under hydrodynamic conditions as shown in Fig. 1b. In fact, under hydrodynamic conditions the pressure potential gradient can take any direction in subsurface space determined by the geometry and values of the permeability and the boundary conditions present.

Weyer (1978) had already shown (compare Fig. 2) that, under recharge areas, the pressure potential forces would be directed downwards in layers with permeabilities so low that the energy gained by vertical position change 


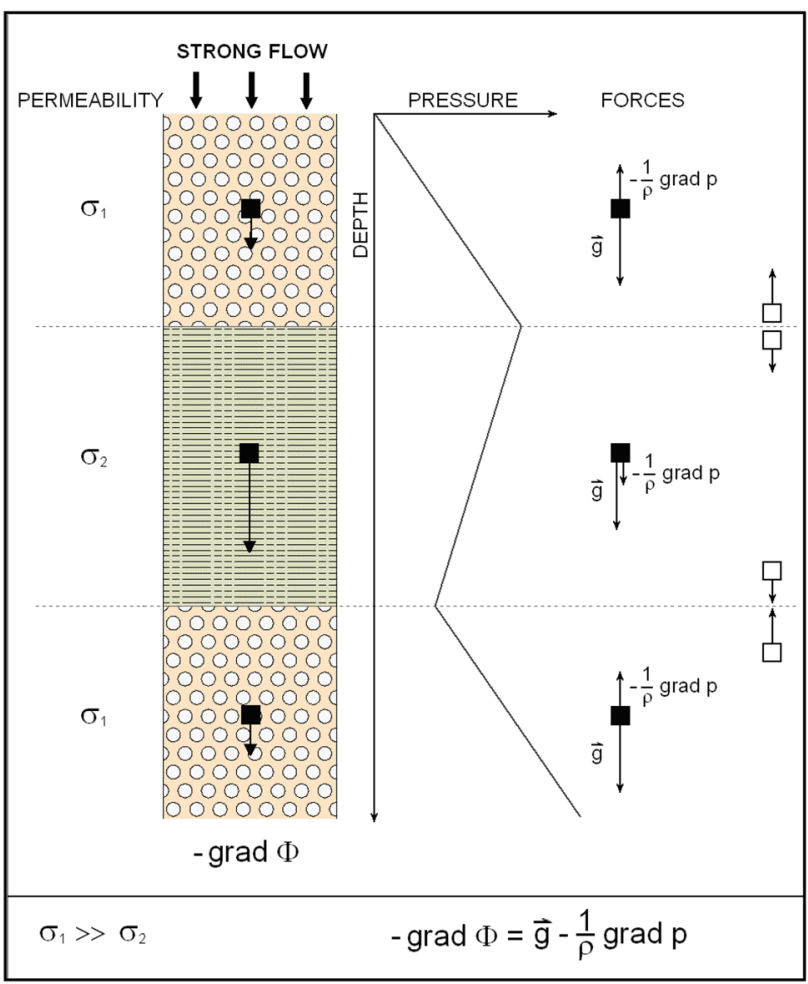

Fig. 2 Distribution of forces characterizing 'Buoyancy Reversal' $[-\operatorname{grad} p=$ hydraulic force; $-g=$ gravitational force; $[-(1 / \rho)$ ( $\mathrm{grad}$ $p)]=$ pressure potential force]. Within the middle layer, the direction of the 'buoyancy force' for lighter fluids is downwards, not upwards. It is upwards in the layers above and below. [Compare force indicators on the far right hand side of the diagram] These conditions create a hydraulic trap for petroleum and $\mathrm{CO}_{2}$. Modified from Weyer (1978, Fig. 9b) and first published in Weyer (2010, Chap 4, Fig. 7). The permeability symbol $\sigma$ follows Hubbert's (1957) notation for the 'volume conductivity of the system'

in the gravitational field is not sufficient to transport the amount of water, received from higher permeable layers above, through the lower permeable middle layer below. Under such conditions the additional energy necessary is taken from the compression of the water mass. As a consequence, the hydraulic pressure potential force is directed downwards and added to the gravitational force vector, causing:

- the transmission of the flow received from above through the low permeable middle layer,

- the transmission of any hydrocarbons from the low permeable middle layer into the underlying high permeable layer,

- the low permeable layer to block any further upward migration of hydrocarbons from deeper layers, thus acting as an impermeable cap rock (barrier) for the accu- mulation of hydrocarbons released from deeper layers, and, as a matter of completeness,

- rendering the top of the low permeable middle layer as the predestined slide surface for earth slides, in particular in response to major rain precipitation events (Fig. 2: arrows at the right hand side, positioned at the boundary of layers).

The informal table above refers to the effect hydraulic forces exert on landslide development on top of low permeable layers with buoyancy reversal as the oft-encountered preferred slide surface upon substantial rain events.

Making use of force potentials Frind and Molson (2010) simulated Weyer's (1978) concept of buoyancy reversal in a mathematical model of groundwater flow within a crosssectional profile. When calculating the vertical pressure distribution through the low permeable middle layer they found Weyer's (1978) concept confirmed as indicated in pressure heads profiles at the bottom of Fig. 3. Under the recharge area the pressure was reduced in the low permeable middle layer due to transfer of compressed energy to the force vector necessary to maintain the flow downwards through the lower permeable middle layer of the amount of groundwater received from above.

Under the discharge area, the necessary upward flow of an equivalent amount of groundwater is maintained by a higher gradient within the low permeable middle layer. Thus, the mathematical model confirmed Weyer's (1978) physical concept of buoyancy reversal and contradicted the solely mathematically formulated physical assumptions of Provost et al. (2018). This confirms that Provost's et al. (2018) assumptions do not reflect the physical reality, but instead are founded on incorrect physical-mathematical assumptions.

As shown in Fig. 4, Weyer (2010) applied the concept of buoyancy reversal to real world field data from the wider oil sands area of Northern Alberta provided by Hitchon et al. (1989). In the diagram the upper triangle represents the data range where buoyancy reversal occurs while the lower triangle represents the data range where buoyancy reversal does not occur. For more information on buoyancy reversal consult Weyer (2018). As a consequence, the generally applied concept of Provost et al. (2018) of upward-directed buoyancy-equivalent hydraulic forces has been shown to be physically invalid rendering all presently existing and applied computer programs also to be invalid under the conditions of buoyancy reversal. They have to be modified to recognize and apply the concept of buoyancy reversal as well as the correct, mostly non-vertical direction of the 'buoyancy' equivalent hydraulic force. The invalid physical assumption that there exists in the subsurface a generally upwards-directed pressure potential force needs to be replaced by codes taking the actual direction 
Fig. 3 Natural groundwater flow system penetrating an aquitard, creating pressure reduction in the aquitard and thereby 'Buoyancy Reversal' below the recharge area with downward flow (figure taken from Frind and Molson 2010, Fig. 7)
Fig. 4 Field example Clearwater-Wilrich aquitard: occurrence of Buoyancy Reversal [BR] under vertical downward flow conditions of freshwater assumed to be at $20{ }^{\circ} \mathrm{C}$ and with the related density and viscosity. (From Weyer 2010, applying data extracted from Hitchon et al. 1989)

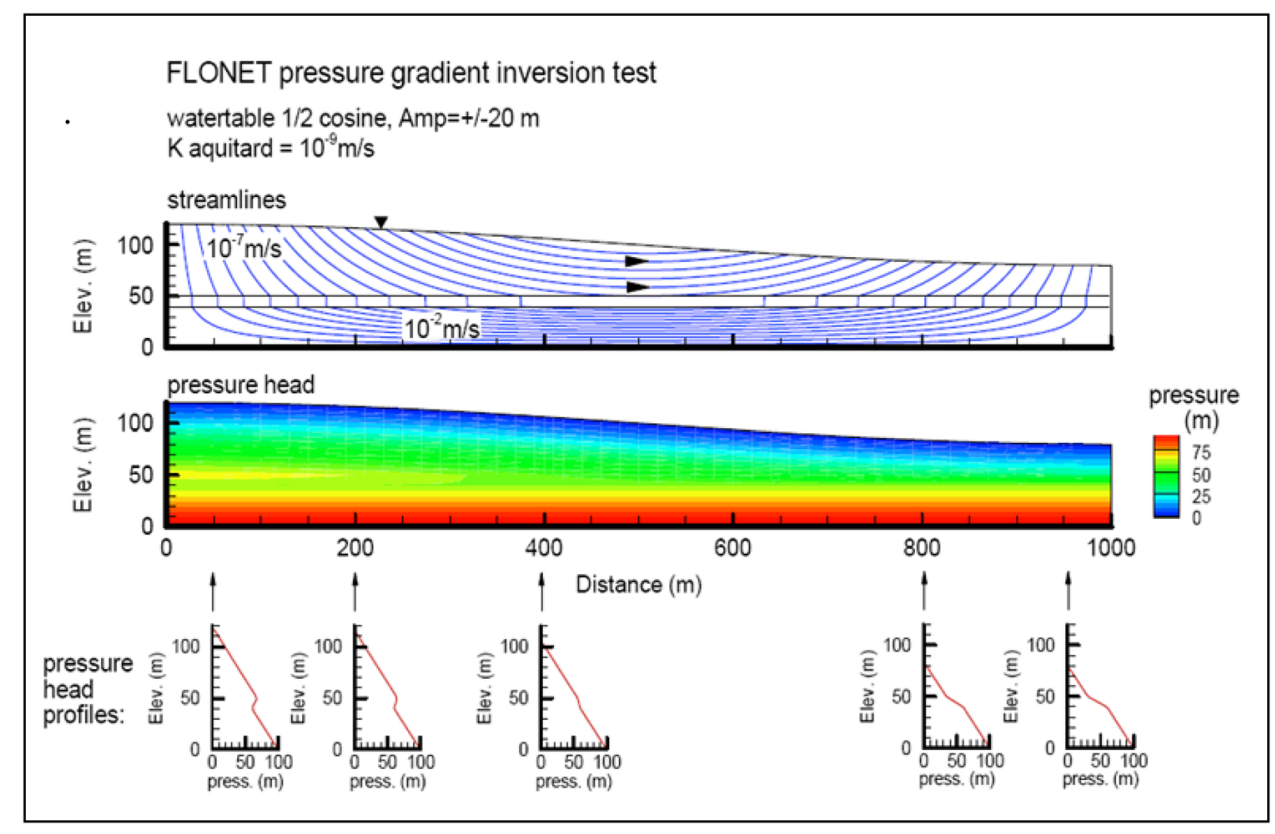

Hydraulic Conductivity (K)

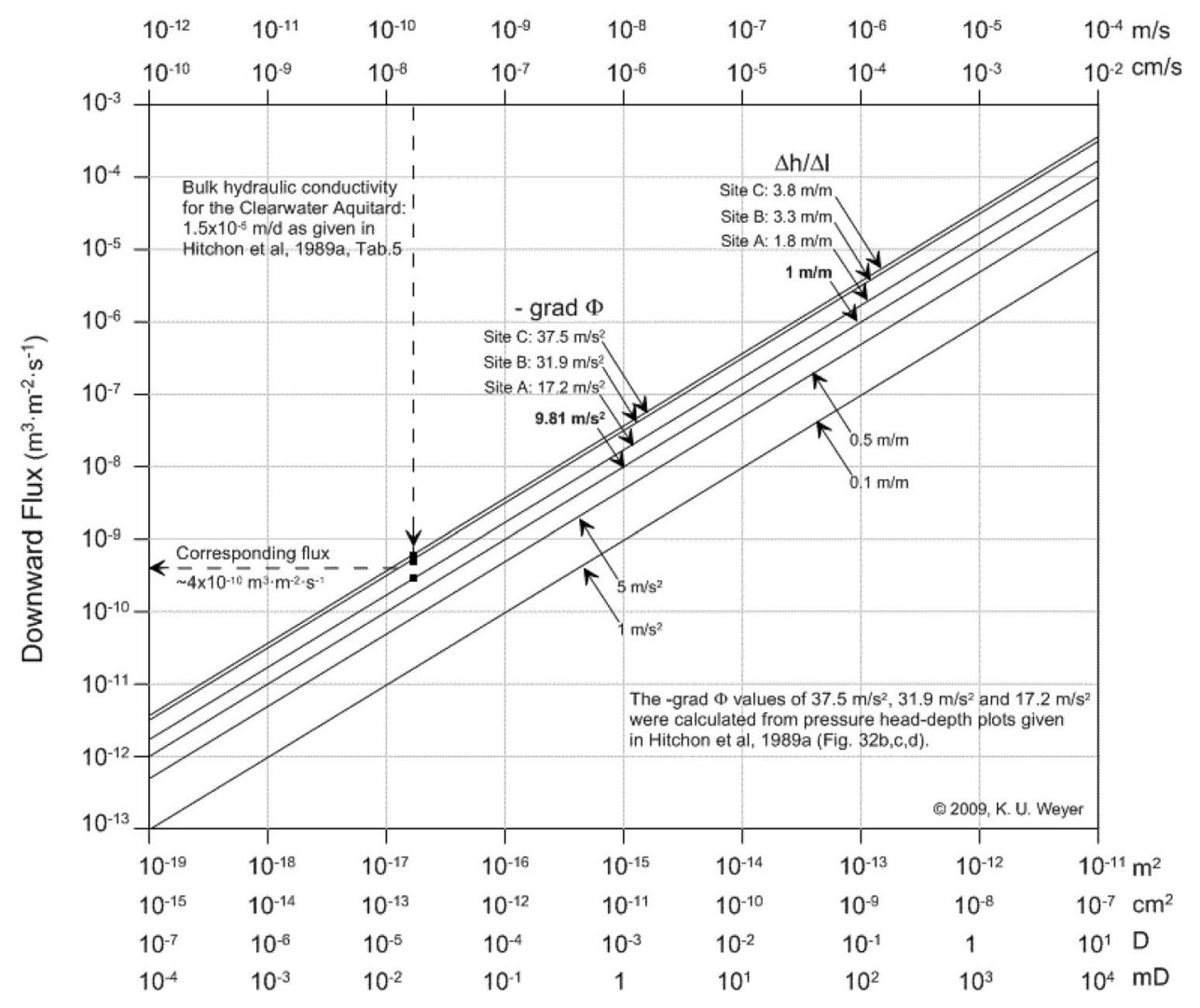

Intrinsic Permeability (k) 
of the 'buoyancy' equivalent force into account. Presently there does not exist one code able to do this. The necessary steps for re-programming these codes have been outlined by Weyer (2019) to adopt them to force potentials. These adaptations constitute a major change in our understanding of the physics and pattern of the subsurface flow of fluids.

\section{Conclusions}

Provost et al. (2018) fail to make their point. The computer programs used by them and those of others need to be adopted to correct physics and thereby to the pattern of groundwater flow systems as they exist on the Florida Peninsula and elsewhere worldwide. The investigations and understanding of groundwater flow pattern at coastal water supply systems, and possibly others, need to be reexamined and, if necessary, adopted to regional groundwater flow systems and their modification by large-scale pumping and the thereby induced pattern of salt water penetration from depth and from the sea.

Provost et al. (2018) fell into a wide-spread trap by assuming that mathematics will determine which systems exist and are important in physics. Although mathematics is a necessary and widely used tool in physics it does generally not determine what assumptions are physically valid and which are not.

Within their abstract Provost et al. (2018) state that Weyer (2018) "claims, gravity acts instead along the direction of the pressure gradient". It seems to me that this statement reflects a fundamental misunderstanding by Provost et al. (2018) regarding the physics of groundwater flow and the driving forces involved. I never made such a claim, neither did Hubbert (1940, 1953). Of course the gravity acts vertically downwards under both hydrostatic and hydrodynamic fluid conditions and, under hydrodynamic conditions, not in the opposite direction of the pressure potential force.

Nevertheless, I thank the above authors for providing a thoughtful mathematically based summary of many of the presently held opinions on seawater intrusion, the physics of subsurface flow and, in addition, for quoting some of Hubbert's $(1940,1953)$ basic work which, to a large degree, has been neglected and overshadowed by physically limited competing textbook-opinions since the early 1970s such as those by Bear (1972) and de Marsily (1986).

Acknowledgements Thanks are due to James C. Ellis for reading and commenting upon this manuscript. The two of us have worked together within WDA Consultants Inc. for more than 20 years. With a view to the future of my granddaughters Simone and Sasha and their and follow-up generations I have continued my involvement in science well beyond normal retirement age in the interest of continuing to push for a better framework for the understanding of groundwater flow dynamics.
Open Access This article is distributed under the terms of the Creative Commons Attribution 4.0 International License (http://creativeco mmons.org/licenses/by/4.0/), which permits unrestricted use, distribution, and reproduction in any medium, provided you give appropriate credit to the original author(s) and the source, provide a link to the Creative Commons license, and indicate if changes were made.

\section{References}

Bear J (1972) Dynamics of fluids in porous media (also published in 1988 by Dover Publishing Inc. as an unabridged, corrected re-publication). American Elsevier Publishing Company Inc, New York

Cooper HH Jr, Kohout FA, Henry HH, Glover RE (1964) Sea water in coastal aquifers. US Geological Survey Water-Supply Paper 1613C, p 95. https://pubs.usgs.gov/wsp/1613c/report.pdf)

De Marsily G (1986) Quantitative hydrogeology: groundwater hydrology for engineers. Academic Press, San Diego

Diersch H-JG (2014) FEFLOW: Finite element modeling of flow, mass, and heat transport in porous and fractured media. Springer Publisher, New York

Freeze RA, Witherspoon PA (1967) Theoretical analysis of regional groundwater flow: 2 . Effect of water table configuration and subsurface permeability variation. Water Resour Res 3(2):623-634

Frind EO, Molson JW (2010) Review of "Physical Processes in Carbon Storage" by Udo Weyer, January 11, 2010. Outside review, p 16. http://www.wda-consultants.com/files/frind_and_molson_-_weyer -review-with-figures.pdf)

Henry HR (1964) Effects of dispersion on salt encroachment in coastal aquifers. In: Cooper HH Jr, Kohout FA, Henry H, Glover RE (eds) Sea water in coastal aquifers. US Geological Survey Water-Supply Paper 1613-C, pp C71-C84. https://pubs.usgs.gov/wsp/1613c/ report.pdf)

Hitchon B, Sauveplane CM, Bachu S, Koster EH, Lytviak AT (1989) Hydrogeology of the Swan Hills Area, Alberta: evaluation for deep waste injection, vol 58. Alberta Research Council Bull, Edmonton

Hubbert MK (1940) The theory of groundwater motion. J Geol USA 48(8):785-944

Hubbert MK (1953) Entrapment of petroleum under hydrodynamic conditions. AAPG Bull 37(8):1954-2026

Hubbert MK (1957) Darcy's law and the field equations of the flow of underground fluids. Hydrol Sci J 2(1):23-59. https://doi. org/10.1080/02626665709493062 [also published in 1956 in Petroleum Transactions, AIME, 207:221-239. https://www. onepetro.org/general/SPE-749-G]

Kohout FA (1964) The flow of fresh water and salt water in the Biscayne aquifer of the Miami area, Florida. In: Cooper HH Jr, Kohout FA, Henry H, Glover RE (eds) Sea water in coastal aquifers: relation of salt water to fresh ground water. USGS WaterSupply Paper 1613-C:C12-C32

Langevin CD (2001) Simulation of ground-water discharge to Biscayne Bay, Southeastern Florida. USGS Water-Resources Investigations Report 00-4251, p 137. https://fl.water.usgs.gov/PDF_files/wri00 4251_langevin.pdf

Langevin Ch D, Thorne DT Jr., Dausman AM, Sukop MC, Guo W (2008) SEAWAT Version 4: a computer program for simulation of multi-species solute and heat transport US Geological Survey Techniques and Methods Book 6, Chapter A22, p 39. http://water .usgs.gov/software/ground_water.html

Muskat M (1937) Flow of homogeneous fluids through porous media. McGraw-Hill, New York 
Provost AD, Werner AD, Post VEA, Michael HA, Langevin CD (2018) Rebuttal to "The case of the Biscayne Bay and aquifer near Miami, Florida: density driven flow of seawater or gravitationally driven discharge of deep saline groundwater?" by Weyer (Environ Earth Sci 2018:77:1-16). Environ Earth Sci. https://doi. org/10.1007/s12665-018-7832-5

Springfield VT (1966). Artesian water in Tertiary limestone in the south-eastern states. USGS Professional Paper 517. https://pubs. usgs.gov/pp/0517/report.pdf)

Tóth J (1962) A theory of groundwater motion in small drainage basins in central Alberta, Canada. J Geophys Res 67(11):4375-4387

Tóth J (1963) A theoretical analysis of groundwater flow in small drainage basins. J Geophys Res 68(16):4795-4812

Tóth J (2009) Gravitational systems of groundwater flow: theory, evaluation, utilization. Cambridge University Press, New York

Voss CI, Provost AM (2002) SUTRA, a model for saturated-unsaturated, variable-density ground-water flow with solute or energy transport. Water Resources Investigations Report 02-4231, USGS. https://pubs.er.usgs.gov/publications/wri024321

Weyer KU (1978) Hydraulic forces in permeable media. Mémoires du B.R.G.M. [Bureau Recherches Géologiques et Minière]. 91:285-297, Orléans, France. http://www.wda-consultants.com/ files/weyer_(1978)_-_hydraulic_forces_in_permeable_media.pdf
Weyer KU (2010) Physical processes in geological carbon storage: an introduction with four basic posters. Internet publication. http:// www.wda-consultants.com/files/weyer_(2010)_-_physical_proce sses_in_geological_carbon_storage.pdf

Weyer KU (2017) 'Frog in a well' or a pending paradigm shift in hydrogeology? Grundwasser Zeitschrift der Fachsektion Hydrogeologie 22:63-64. https://doi.org/10.1007/s00767-016-0350-z

Weyer KU (2018) The case of the Biscayne Bay and aquifer near Miami, Florida: density-driven flow of seawater or gravitationally driven discharge of deep saline groundwater? Environ Earth Sci 77:1-16. https://doi.org/10.1007/s12665-017-7169-5

Weyer KU (2019) Simulation of subsurface fluid flow by force potentials. Environ Earth Sci

Weyer KU, Ellis JC (2019) Subsurface investigation and simulation of fluid flow systems by means of force potentials. Springer Publications, New York

Publisher's Note Springer Nature remains neutral with regard to jurisdictional claims in published maps and institutional affiliations. 